\title{
Schizoaffective Disorder and Depression. A Case Study of a Patient from Ceará, Brazil
}

Marcos Eduardo Mendes Braga', Hermes Melo Teixeira Batista ${ }^{2,3}$, Maria Auxiliadora Brasil Sampaio Cardoso', Maria do Socorro Martins Cardoso Novais ${ }^{1}$, João Marcos Ferreira de Lima Silva², Francisca Moraes da Silva', Raul Rodrigues Barros ${ }^{4}$, Woneska Rodrigues Pinheiro ${ }^{1,3}$, José Alexandre de Olim Câmara ${ }^{3}$, Italla Maria Pinheiro Bezerra ${ }^{3}$, Luiz Carlos de Abreu $^{3}$

\section{Abstract}

Introduction: Schizophrenia is a complex clinical syndrome that may present with a great variety of psychopathologic manifestations, covering changes in thought, perception and emotions, as well as motricity and behavioral abnormalities. It symptoms can be divided in positive and negative. Many others psychiatric disturbances share schizophrenia symptoms, among then, Schizoaffective Disorder, with altered mood, as in depression or mania. Although there is, in literature, plenty of evidence about the impact of depressive symptoms in the quality of life in schizophrenic patients, we were unable to identify Brazilian prospects on the subject. Surpassing the findings of other studies, depression in schizophrenic patients has considerable impacts, in addition to its prevalence and frequent underdiagnosis.

Objectives: Report a case of patient with Schizoafective Schizophrenia and Depression, treated in the Psycosocial Care Center (CAPES) III in the city of Juazeiro do Norte, Ceará, Brazil.

Materials and Methods: Case study, with an descriptive transversal approach, realized under the rules of Resolution 466/12, from National Health Council /National Health Ministry regarding legal and ethical aspects about studies with human beings. The study was registered in the Plataform Brasil, and subsequently forwarded for consideration in the Research Ethics Committee, then being approved.
1 Faculdade Leão Sampaio, Juazeiro do Norte, Ceará.

2 Faculdade de Medicina de Juazeiro do Norte, Estácio, Juazeiro do NoprteCeará.

3 ULaboratório de desenho e Escrita Científica da FMABC, Santo André, São Paulo.

4 Universidade Federal do Cariri, Medicina, Barbalha-Ceará.

\section{Contact information:}

Hermes Melo Teixeira Batista.

” hermesmelo@oi.com.br 
Discussion: The patient's life story and background, as reported by herself, can probably not only justify, but also fundaments the disease etiology. Attempts of sexual abuse, familiar negligence, psychiatric disorders in the family, among many other factors, reported by the patient and her relatives, can be potential triggers for her schizophrenia and depression. With new therapeutic approaches, body and psychic improvements begun, and the patients realized that a more healthy life, followed by weigh loss, despite medication usage; in association, the doctor patient-patient relationship has grown in confidence along the way. Finally this case shows the importance of this kind of approach, holistic and focused in the individual, for schizophrenic patients and other psychiatric disorders, because only that way the health care professional can maximize the results of the prescribed therapy.

Conclusions: Throughout this clinical case its possible to know and understand more about the Schizophrenic Disorders. We conclude that the therapeutic approach, executed by a multidisciplinary team, had a positive impact on patient's prognosis. In practical terms, the best kind of assistance is the individualized and humanized, understanding the uniqueness of every patient, respecting them and providing qualified assistance for their biopsychosocial needs.

\section{Keywords}

Schizophrenia; Schizoaffective disorder; Case study.

\section{Indtroduction}

Schizophrenia is a complex clinical syndrome, with a great variety of psychopathological manifestations, covering alterations in thought, perception and emotions, as well as motricity and behavioral abnormalities. It symptoms can be divided in positives (delirium, hallucinations, catatonia, etc.) and negatives (blunted affect, alogia, avolition, etc.), that may predominate according to patient's previous characteristics and time of disease; in as much, chronic cumulative effects of schizophrenia tends to be severe and persistent, with marked social prejudice for those committed [1].

According to Aguiar et al (2010), the etiology of schizophrenia remains unknown and, however there are many theories, there is still no consensus.
The peak of incidence is of 15 to 25 years of age for man, and 25 to 35 years of age for woman [2]. Treatment must be continuous and is recommended for all diagnosed patients [3] (FALKAl, et al, 2006). Antipsychotic drugs have proven to be beneficial for most of psychotic disturbances, but it may be associated with many undesirable effects [4] (HADAD, SHARMA, 1995).

Many other disturbances shares the carachteristics of schizophrenia [5]. Psychotic disturbances similar to schizophrenia, but with less than six months of symptoms are called Schizophreniform Disorders. At initial presentation, it is hard to tell with the patient will have a final diagnosis of schizophrenia or schizophreniform disorder. (Esquizofrenia e Transtornos Psicóticos, 2015). When symptoms are present for 
more than a day but less than a month, it can be classified as a Brief Psychotic Disorders, and usually is triggered by stressing situations [6]

Psychiatric disorder characterized by the presence of humor alterations, as depression or mania, along with typical symptoms of schizophrenia is classified as a Schizoaffective Disorder [5].

According to Souza and Coutinho (2006), attention must be raised in schizophrenic patients presenting anxiety and depressive symptoms, considering that those manifestations usually have the same -or even greater- impact on their quality life than negative and positive symptoms of schizophrenia. Specific therapeutic approach to those patients may implicate considerable improvement in quality of life [1].

In the Portugal Psychiatric Census, those patients searched more frequently for Health Care Services $(21,2 \%)$ and, paired with depression, Eschizophrenia is responsible for $60 \%$ of the country's suicide's rate [7]. Internationally, the prevalence of depression in schizophrenic patients varies from 7 to $70 \%$, media of $25 \%$. In Brazil, the prevalence is estimated to be around 27 to $29,8 \%$ [8]. Despite its clinical relevance, the studies estimates that about half of the cases of depression are not diagnosed in the primary levels of health care services [9].

Even though the literature has established the impact of depressive symptoms in the quality of life in the patients with schizophrenia, we were unable to identify Brazilian data on the subject. The subjective is pertinent when considered the therapeutic approaches, including drug's prescription, and its positive impact on these specific population when depression is precociously identified [10]. With proper treatment, morbimortality associated with depression can decrease about 70\% [11].

Souza and Coutinho (2006) stated that Schizophrenia is a paradigmatic disease in Psychiatry. The progressive transformation of psychiatric assistance is still faced with the idea that the evolution of mental disorders depends solely on the classic variables related to the biomedical model, already outdated, ignoring all the biopsychosocial context in which the carrier is inserted. This concept shall be overcome permanently [1, 12].

Considering this background and the positive impacts of the interventions, it is important to deepen the studies on depression and schizophrenia. In this article, we report a case of a patient suffering from Schizoaffective Schizophrenia in psychiatric treatment at the Centro de Atenção Psicossocial III (CAPES), in the city of Juazeiro do Norte -Ceará.

Schizophrenia is a complex disease, with multiple causes and contexts, some of them still undifinied -which reinforces the importance of study it more. A compilation of case studies about schizophrenia and depression could be a valious source of information about schizophrenia, helpening to clarify some points and favoring construction of consensus about it's etiology, pathophysiology, therapeutic management and prognosis.

Our study considered, as initial question: Being schizophrenia a multifactorial disease, what were the causes that triggered the disease in the patient, specifically with an schizoid spectrum?

The relevance of the study lies in the instruments it can provide for the investigation of schizoid schizophrenia, throughout a clinical report, with an humanized focus to the biopsychosocial of the patient.

We hope to contribute for the dissemination of theme and its study, raising its visibility, considering the rareness of reports about the professional approach with those patients, despite numerous studies about objective definitions

We assume, as a hypotesis, that social, familial and religious influences, but especially the violent background on the patient's story have act as triggers for schizophrenia, reinforce the multifactorial theory for the origin of schizophrenia and depression. 


\section{Objectives}

To report a case of a patient diagnosed with Schizoaffective Schzophrenia and depression, following treatment in the Centro de Atenção Psicossocial III in the city of Juazeiro do Norte, Ceará, Brazil. Describe associated factors to the raise of schizophrenia for the considered patients, including its familial relations. Understand the importance of drug therapy in the treatment of schizophrenia. Review the literature about the main therapeutic strategies for improving quality of life of schizophrenic patients.

\section{Methodology}

Descriptive and transversal case study, with qualitative approach, to obtain data on the patients clinical history. The data was obtained with a clinical interview with the patient, held in February 2nd, 2015 and February 4th, 2015, at CAPES III, during her usual therapy sessions.

\section{Case report}

M.C.B.G, female, 29 years old, white, from Asssaré -Ceará, living in Juazeiro do Norte- Ceará. Had a first visit to office in the CAPES III in March $9^{\text {th }} 2006$, for semi-intensive treatment for audio and visual hallucinations, delirious and megalomaniac ideas, with initial diagnostic hypothesis of schizophrenia.

Patient told us that the trigger of her "problems" was an attempt of sexual abuse, suffered when she was 16 years old and lived in Rio de Janeiro - RJ. Even though she said it was a frustrated attempt, the unpleasant experience changed her from this moment and on, and made her "like that".

Researchers have never come to a consensus about the definitive cause of schizophrenia; it is known that it is a multifactorial disease, even when it has a sudden beginning. Some situations, depending on its force and frequency, can act like triggers to symptoms that was previously unnoticed for most people.

MC.BG. has an active social life, engaged in religious groups, practice physical exercises regularly (following medical orders) but still has difficult in her familial relationships. She lives with her husband, who also is a patient in CAPS III, in a rented house, provided with basic services. She told us her dream was to become a mother on day, being whiling to face all difficults that eventually come with it, including in her treatment, being aware of her limitations as an schizophrenic and conscious about the need of never stopping her medications.

She is on medical for longer than six years. She denies any other morbid past history. Is independent in her basic and elementary diary life tasks, as breathing, eating, evacuating, moving, dressing and undressing her clothes. Usually has four meils in a day, with no alimentary restrictions. She denies use of psychoactive substances (alcohol, tobacco and illegal drugs). She refers important weight gain after schizophrenia's treatment.

She reports a familial medical history of psychiatric problems in her mother and drug abuse (alcohol and illegal drugs) in her brother. She was collaborative and fully comunicative during the interview. She has a good hygiene patterns, with daily showers.

Her physical exam had no significant alterations. Routine laboratorial exams were also normal. She was currently using $2 \mathrm{mg}$ daily of Risperidone, $100 \mathrm{mg}$ of Clorpromazine (coloquei o nome da substância, pois Amplictil é nome do Mercado brasileiro) and $20 \mathrm{mg}$ of Omeprazole.

\section{Mental Exam \\ General}

- Appearence: patient presented with good hygiene conditions. She was calm and collaborative, with her eyes down, but with a penetrating looking towards the interviewers.

- Verbal action: she demonstrated a coherent speech, with organized and spontaneous thoughts, but with and fast changes of subject, making some her lines incomprehensible sometimes.

- Humor, sentiment and affect: Patient presents with stable humor and adequated affect. 
- Perception: patient presents (no momento da entrevista??) disturbed perception, manifested by hallucinations and delirious.

Thinking process: she displays organized thoughts and ideias, but with an accelerated course.

\section{Sensory and Cognition}

- Consciousness: patient was conscious.

- Orientation: she appeared to be oriented about time, place and person.

- Concentration and cognition: Due to the limited time we had with the patient, it is difficult to know if she has difficult in accomplishing her group therapy's activities, but, according with herself, she has trouble in some tasks, as in reading a book, for an example.

- Memory: no altered memory was noticed during evaluation.

- Inteligence: good level of intelectuality, according to the interviewers.

- Insight: Sheis aware of her moments of "crisis". She has an expectative of getting healed. She admits that she is "fine", and thinks she is not able to leaving the health care service because of her husband, whom sometimes also get into "crisis".

- Credibility: Comparing the data presented by the patient in the interview, and the data verified in medical registries that is no incongruences. There so, the patient has credibility reporting her situation clearly.

To help in the patient assistance, the Matricidal Support Team of Núcleo de Apoio à Saúde da Família (NASF) -a support service to basic health care assessments- to collaborate with a singular therapeutic plan that could help her best. After initial evaluation, patient Body Mass Index (BMI) was found to be compatible with Grade I Obesity, and she had an appointment with a Nutritionist, who prescribed her a healthier diet to help in weight control. A physical educating professional was also called and oriented the patient about exercise practice that was adequate for her.
Psychiatrists and Psychologists of CAPS III were also involved in the therapeutic plan, contributing to patients improvement in self-steem and familial relationships. The Centro de Referência de Assistência Social (CRAS) - a social assistence service - was also invited to contribute, and was able to involve the patient and the patient's family in activities that improved family linkages - the patients' mother and brother were actively searched and included for evaluation and treatment in proper Psychosocial Centers (in the brother's case, in the CAPS Alcohol and Drugs).

The patient was also referred to an obstetric evaluation, regarding her gestational desire and treatment adjustments in case she gets pregnant. Currently, she is following treatment for Polycistic Ovaries Syndrome and fertilization, so she can become a mother. She has lost 3 kilograms after the Singular Therapeutic Plan and is optimistic to achieve her ideal weight.

Patients have a good and trusty relationship with the assistance professionals, adhering properly to the agreed therapeutic plan. She is still engaged with her religious group, is following her diet and exercises daily in a gym near to her house and also has frequent water aerobics classes. After new laboratorial tests, her levels of total cholesterol, HDLcholesterol and triglycerides have decreased. Her mother is also following treatment in the CAPS III, but her brother left his treatment in his drug addiected suport group. There so, the relationship with her mother and other relatives was straightened after the insertion in the therapeutic groups in the CRAS. M.C.B.G presented improvements in ther cognition, concentrative capacitive and self-stem. Yet she reports important gastric symptoms during treatment, despite the use of Omeprazole.

\section{Discussion}

Patients diagnosis was based in her symptoms of delirious, hallucinations (auditory and visual) and megalomaniac ideas. Schizoaffective disorders was 
also diagnosed, according to the observed and reported symptoms during patients follow-up by the CAPS III team, that included profound apathy and social isolation.

The patients' life trajectory by itself may have contributed to the development of Schizophrenia. Sexual abuse (even if partialy frustrated), familial negligence and first degree history of psychiatric disorders, family disruption, among many other factors reported by the patient an her relatives can act as potential triggers for schizophrenia and depression.

According to Silva (2006), schizophrenia is an hereditary disease. Having a parent suffering with the disease is the most consistent and important risk factor to develop schizophrenia. A clear relationship can be found between risk of schizophrenia and degree of kinship to a sick relative [13].

The relatively stable financial situation -after inclusion in welfare policies- brought tranquility to the patient and her husband. There were no reports of arguments or disagreements between the couple, which probable helped in their assiduity to the activities in CAPS III.

A proposed factor for her schizoaffective disorder is the presence of gynecological problems that hinder the achievement of pregnancy. Meantime, the impossibility of stopping her anti-psychotic meds can interfere importantly in an eventual pregnancy.

Currently, the efforts of the team were increased to help patients, as the one reported in here, that are in the wiling of having children. It is believed that achieving their dreams is important to reduce symptoms of both schizophrenia and depression, as the follow-up is maintained during periods of sensitive changes.

Weight gain is another factor contributing to lowering patient's self-stem in general and in depression. Sedenctarism, unbalanced diet and the use of certain anti-psychotic drugs acts sinergically towards weight gain and are very common in schizophrenic patients [14]. According to Atuxx et al. (2009) drug therapy can contribute to weight loss, however, an multimodal approach to weight control, with contextualized flexibility, may produce better results [14].

In the present case, the adoption of a few measures -allied to the strengthening of ties with the assistance team- were able to help the patient achieve body and psychic changes, making her realize that a healthier lifestyle is possible and that she can lose weight despite the use of medication.

Finally, with this case's results, the importance of an individual and holystic approach, for patients with schizophrenia and other psychotic disorders, is reinforced.

\section{Typically Schizoaffective Schizphrenia}

Despite the fact that schizophrenic patients also suffering from depression have presented an diminished scores of quality of life, the patterns was similiar to those of schizophrenic patients not suffering from depression. Regarding the satisfaction with their work, religion, safety and finances, there were no significant differences between schizophrenic patients who were and weren't suffering of depression [15].

According to González and Pinto (1998), during its initial stages or in transversal evaluation, the Schizoaffective Disorder diagnosis can be a complex task, especially in face of its many differential diagnosis in the psychotic disorders spectrum [16].

Many studies have suggested that patients with Schizoaffective disorder and schizophrenia have more in common with those having only schizophrenia than with those with bipolar disorder, especially in the initial stages. However, cognitive and perception disturbances were more intense in schizophrenics than in patients with schizoaffective disorders and bipolar depression [17].

Those same studies indicate that the variables related to clinical evolution in the three groups are more related between schizoaffective disorder and bipolar disease, despite the fact that the acute symptoms are more similiar between schizophrenia 
and schizoaffective disorder. The percent of hospitalization were similar in the three groups [18].

The pharmacological treatment of Schizoaffective Disorder is based on anti-psychotic drugs, humor stabilizers and anti-depressives. Clinical trials usually considered patients with humor disorders and schizophrenia, being hard to find in the literature studies considering only schizoaffective disorder patients [19-23].

Depression is frequently associated with a low self-stem, future incertaints and a feeling that "life is hard", exercing negative influence in the patients perception of his quality of life. Besides that, the evaluation of depressive symptoms in schizophrenic patients is hard, since its symptoms are "contaminated" by the negative manifestations of schizophrenia itself or extrapyramidal symptoms, which represent a frequent source of bias [1, 24-27].

Greater attention must be dismissed to patients with anxiety and depressive symptoms and schizophrenia, considering its greater impact in ther quality of life -even bigger than negative and positive symptoms of schizophrenia. These are potentially modifiable factors, when specific therapeutics are adopted- which can imply in significant improvements in quality of life in this population [1, 28-30].

The psychiatrist is one of the professionals that can contribute the most for the improvement in those patients' clinical condition. The psychiatric treatment must be associated with a multiprofessional team assistance, which reinforces the importance of the intersectoriality of health care systems for the treatment and follow up of those cases [30].

\section{Conclusions}

Throughout this case it is possible to understand more about th Schizoaffective Disorders. Inasmuch, these paper showed an holistic vision in the patient's assistance, with as medical approach there is more than just "technique and drugs".
The followed approach, realized with a multiprofessional assistance team, was favorable to the patients prognosis. In clinical practice, and individual-focalized and humanized approach, assisting the patient as singular being, that deserves respect and qualified assistance, is the best one achieving their biopsychosocial needs.

Promotion of health care is not made necessarily only through technical procedures, in a hospital bed or in an office. Listening carefully, involving the family, respecting the patients, their ills, achieving confidence and straightening linkages are elements that can be used to improve the quality of assistance, especially in psychiatric patients.

\section{Legal and Ethical Aspects}

The presented study followed all the determinations of Resolution 466/12 of the National Coucil of Health/Ministry of Health. The study was sent to Plataforma Brasil and than to local Ethics Committee for Researches involving Human Beings, being finally approved. The patient have authorized the present study and its use for scientific porpose, having signing the Informed Consent Form.

\section{References}

1. Souza LA, Coutinho ESF. Fatores associados à qualidade de vida de pacientes com esquizofrenia. Revista Brasileira de Psiquiatria. Rio de Janeiro, 2006; 28(1): 50-8.

2. Videbeck SL. Enfermagem em saúde mental e psiquiatria. 5. ed. Porto Alegre: Artmed, 2012.

3. Shirakawa Al. Aspectos gerais do manejo do tratamento de pacientes com esquizofrenia. Revista Brasileira de Psiquiatria. 2000; 22(1): 56-8

4. Tostes LRM, Moraes LRN. Esquizofrenia: curso, evolução e prognóstico. Jornal Brasileiro de Psiquiatria. 1989; 38(4): 233-9

5. Maccay E, Ryan K, Amey S. Mitiganting Engulfment: recovering from a first episode of psychosis. J Psychosoc Nurs. 1996; 34(11): 40-4.

6. Barreto J, Carvalho C. Perturbação psicótica breve. Disponível em: $<$ http://neuroclnica.blogspot.com.br/2009/06/perturbacaopsicotica-breve.html>. Acesso em: 27/Janeiro/2015. 
7. Gomes EA. Atividade física e desportiva para indivíduos com Esquizofrenia ou Transtorno Esquizoafetivo: implantação de um programa e análise da aplicabilidade de um teste de capacidade funcional. 2011, 81f. Tese (Mestrado em Ciências do Desporto) - Faculdade de Desporto/Universidade do Porto, Porto, 2011.

8. Bardin L, Análise de conteúdo. Lisboa (Po): Editora Edições 70; 2000.

9. Fleck MPA et al. Associação entresintomas depressivos e funcionamento social emcuidados primários à saúde. Rev Saúde Pública 2002; 36: 431-8.

10. Sullivan G, Wells KB, Leak B. Clinical factors associated with better quality of life in a seriously mentally ill population. Hospital Community Psychiatry 1992; 43 794-8.

11. Cardoso CS et al. Depressão na esquizofrenia: prevalência e relação com a qualidade de vida. Cad. Saúde Pública, Rio de Janeiro. 2007; 23(9): 2035-48.

12. Leal EM et al. Psicopatologia da autonomia: a importância do conhecimento psicopatológico nos novos dispositivos de assistência psiquiátrica. Revista Latinoamericana de Psicopatologia Fundamental, São Paulo. 2006; 9(3): 433-46.

13. Silva RCB. Esquizofrenia: Uma Revisão. Psicologia USP, 2006, 17(4), 263-285.

14. Attux C, Martini LC, Reis $A F$, Bressan RA. Intervenções não farmacológicaspara manejo do ganho de pesoem pacientes com esquizofreniaem uso de antipsicóticos. Arq Bras Endocrinol Metab. 2009; 53-4

15. Evans S, Huxley P, Proebe SA. Comparison of the quality of life ofseverely mentally ill people in UK \& German samples. Int J Soc Psychiatry. 2000; 46(1): 47-56.

16. González-Pinto A, Gutierrez M, Mosquera F et al. - First Episode in Bipolar Disorder: Misdiagnosis andPsychotic Symptoms. J Affect Disord. 50(1): 41-44, 1998.

17. Ricca V, Galassi F, La Malfa G et al. - Assessment of BasicSymptoms in Schizophrenia, Schizoaffective andBipolar Disorders. Psychopathology. 1997; 30(1): 53-58,

18. Benabarre A, Vieta E, Colom F et al. Bipolar Disorder, Schizoaffective Disorder and Schizophrenia: Epidemiologic, Clinical and Prognostic Differences. Eur Psychiatry. 2001; 16(3): 167-172.

19. Quarantini LC, Sena EP, Oliveira IR. Tratamento Do Transtorno Esquizoafetivo. Rev. Psiq. Clín. 2005; 32(1): 89-97.

20. Cordiolli AV, Zimmermann HH, Kessler F. Rotina de Avaliação do Estado Mental. Disponível em: http://www.ufrgs.br/psiquiatria/ psiq/Avalia\%C3\%A7\%C3\%A30\%20\%20do\%20Estado\%20 Mental.pdf. Acesso em: 27/Janeiro/2015.

21. Denzin NK, Lincoln YS. O planejamento da pesquisa qualitativa: teorias e abordagens. 2 ed. Porto Alegre: Artmed, 2006.

22. Durão AMS, Souza MCBM, Miasso Al. Cotidiano de portadores deesquizofrenia após uso declozapina e acompanhamento grupal. Revista Latino-americana de Enfermagem, 2006; 14(4): 586-92.
23. Fernandes TG, Passos TR, Costa Júnior VL. O uso indevido do Omeprazol. - São Paulo: I Simpósio De Ciências Farmacêuticas/ Centro Universitário São Camilo, 2012.

24. Giacon BCC, Galera SAF. Ajustamento familiar após o surgimento da esquizofrenia. Rev ESC Enferm USP, 2006; 40(2): 286-91.

25. Gil AC. Como elaborar projetos de pesquisa. 4. ed. São Paulo: Atlas, 2008.

26. Hebert y Meltzer MD. Psychopharmacology: The third generation of progress.3. ed., Reven press, New York, 1987.

27. Marconi MA, Lakatos EM. Fundamentos da Metodologia científica. 7 ed. São Paulo: Atlas, 2010.

28. Moreira CS, Mezzasalma MA, Juliboni RV. Esquizofrenia Paranóide: Relato de Caso e Revisão da Leitura. Revista Científica da FMC - 2008; 3(2).

29. Aguiar CCT et al. Esquizofrenia: uma doença inflamatória? Jornal brasileiro de Psiquiatria, 2010; 59(1).

30. Oliveira RM, Facina PCBR, Siqueira Júnior AC. Revista Brasileira de Enfermagem. Brasília, 2012; 65(2): 309-16.

\section{Comment on this article:}

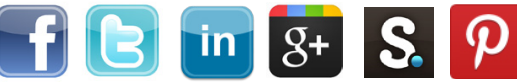

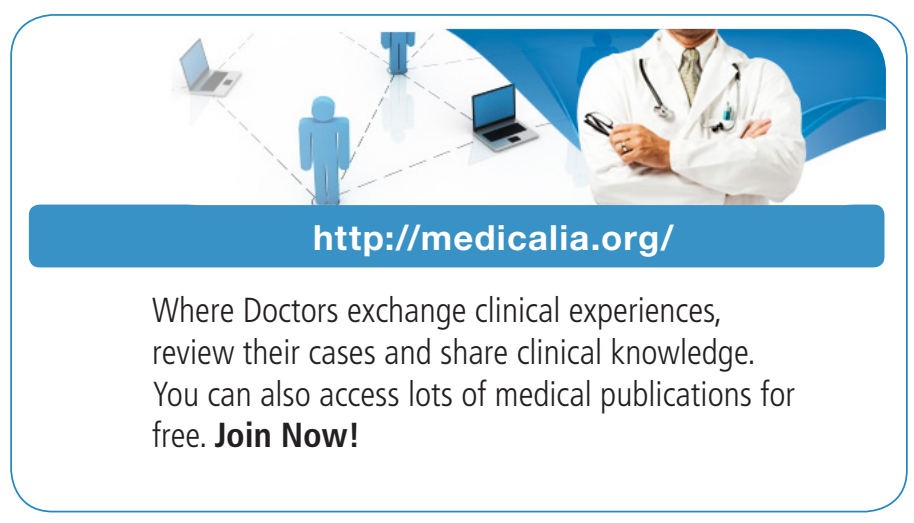

Publish with iMedPub

\section{http://www.imed.pub}

International Archives of Medicine is an open access journal publishing articles encompassing all aspects of medical science and clinical practice. IAM is considered a megajournal with independent sections on all areas of medicine. IAM is a really international journal with authors and board members from all around the world. The journal is widely indexed and classified Q1 in category Medicine. 